\title{
Large-Scale Fabrication of Ordered Nanobowl Arrays
}

2004

Vol. 4, No. 11

2223-2226

\author{
Xu Dong Wang, Elton Graugnard, Jeffrey S. King, Zhong Lin Wang, ${ }^{*}$ and \\ Christopher J. Summers*
}

Center for Nanoscience and Nanotechnology, School of Materials Science and

Engineering, Georgia Institute of Technology, Atlanta, Georgia 30332-0245

Received August 31, 2004; Revised Manuscript Received September 17, 2004

\begin{abstract}
A novel approach is presented for the large-scale fabrication of ordered $\mathrm{TiO}_{2}$ nanobowl arrays. The process starts with a self-assembled monolayer of polystyrene spheres, which is used as a template for atomic layer deposition of a $\mathrm{TiO}_{2}$ layer. After ion-milling, toluene-etching, and annealing of the $\mathrm{TiO}_{2}$-coated spheres, ordered arrays of nanostructured $\mathrm{TiO}_{2}$ nanobowls have been fabricated. The nanobowls exhibit smooth interior and exterior surfaces and uniform sizes and thickness. The nanobowl arrays have been demonstrated to be useful for selecting spheres smaller than the inner diameter of the bowls. This approach can be extended to a wide range of coating materials and substrates (ceramics, metals, polymers, glasses) with controlled wall thickness and size.
\end{abstract}

Monolayer self-assembly (MSA) of polystyrene (PS) submicron spheres on a flat substrate ${ }^{1,2}$ is an effective and economical technique for fabricating patterns on a relatively large scale. ${ }^{3,4}$ The catalyst pattern created by MSA has been applied for growing aligned and spatial-distribution controlled carbon nanotubes ${ }^{5}$ and oxide nanorods. ${ }^{6}$ Atomic layer deposition (ALD), in which film growth is a cyclic, multistep process of alternating surface-limited chemical reactions, has been demonstrated to be a powerful technique for fabrication of high-quality and multifunctional thin films on various substrates. ${ }^{7,8}$ A diversity of nanostructures can be synthesized using ALD owing to its wide operation temperature and precursor adaptability. For example, by controlling the thickness of the uniformly deposited films, a templateassisted ALD process has been applied to the fabrication of inverse opal structures ${ }^{9,10}$ and quasi-one-dimensional (1D) nanostructures. ${ }^{11,12}$

In this paper, we present a process that utilizes MSA and ALD for fabricating arrays of $\mathrm{TiO}_{2}$ nanobowls. The $\mathrm{TiO}_{2}$ nanobowls exhibit smooth surfaces and uniform size and thickness. The nanobowls may be used as ultra small containers for holding fluid of nanoscale volume, and are also demonstrated to be useful for the size selection of submicron spheres. The approach presented could be extended to a wide range of coating materials and substrates with controlled wall thickness and size.

The experimental procedures are schematically illustrated in Figure 1. First, a monolayer of highly ordered PS spheres (505 $\mathrm{nm}$ in diameter) was self-assembled onto a sapphire substrate $(5 \mathrm{~mm} \times 5 \mathrm{~mm})$ using a technique we reported

\footnotetext{
* Corresponding authors. E-mail: zhong.wang@mse.gatech.edu (ZLW), chris.summers@mse.gatech.edu (CJS).
}

(a)

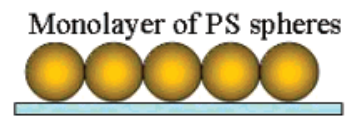

(c) Ion beam milling

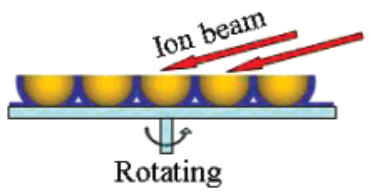

(b) ALD of $\mathrm{TiO}_{2}$ layer

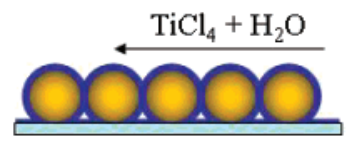

(d) Toluene etching

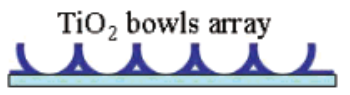

Figure 1. Experimental procedure for fabricating $\mathrm{TiO}_{2}$ nanobowl arrays.

previously $^{6}$ (Figure 1a). The substrate was placed at the center of an ALD chamber, which was kept at $80{ }^{\circ} \mathrm{C}$ during the entire growth process. Then, pulses of $\mathrm{TiCl}_{4}$ vapor and $\mathrm{H}_{2} \mathrm{O}$ vapor were introduced sequentially into the chamber under a vacuum of $4.5 \times 10^{-3}$ Torr. The pulse duration was $4 \mathrm{~s}$ for each precursor, and the pulses were separated by a $\mathrm{N}_{2}$ purging gas for $10 \mathrm{~s}$. A $\mathrm{TiO}_{2}$ layer was slowly grown on the surfaces of the PS spheres and the substrate (Figure 1b). The growth was terminated after 200 pulse cycles, which produced a uniform amorphous $\mathrm{TiO}_{2}$ layer $\sim 20 \mathrm{~nm}$ in thickness. The estimated growth per cycle was $0.1 \mathrm{~nm}$, which was determined experimentally from the planar growth per cycle of $\mathrm{TiO}_{2}$ on natively oxidized $\mathrm{Si}(100)$ substrates at $100{ }^{\circ} \mathrm{C} .{ }^{13}$

Second, an ion milling machine was used to remove the top half of the $\mathrm{TiO}_{2}$-coated PS spheres. A $5 \mathrm{kV}, 15 \mathrm{~mA}$ ion 

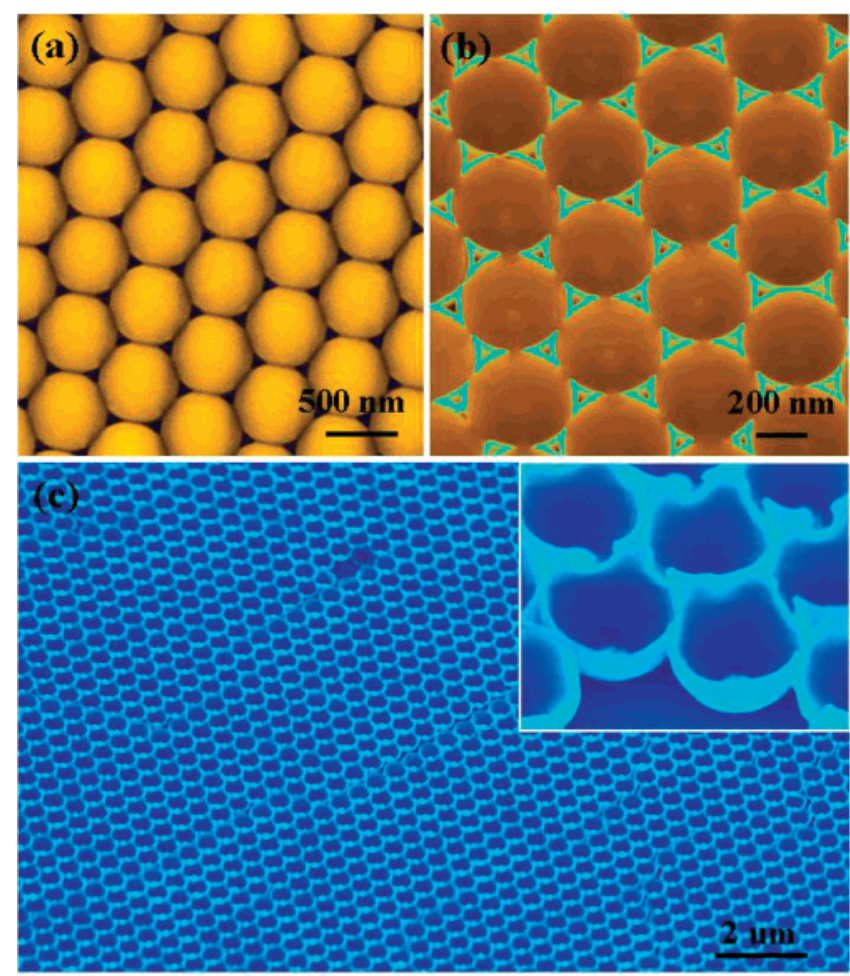

Figure 2. SEM images at each step of the fabrication process. (a) Monolayer self-assembly of polystyrene spheres coated with $\mathrm{TiO}_{2}$. (b) Ion beam milled surface of $\mathrm{TiO}_{2}$ coated polystyrene spheres. (c) Low and high (inset) magnification SEM image of $\mathrm{TiO}_{2}$ nanobowl arrays.

beam was incident on the sample surface at an angle of $10^{\circ}$ while the sample was continuously rotated without cooling (Figure 1c). After 20 min of continuous milling, the top half of the spheres was evenly removed. Finally, the PS hemispheres left on the substrate were etched by toluene, resulting in a highly ordered array of $\mathrm{TiO}_{2}$ nanobowls (Figure 1d). Annealing at $850^{\circ} \mathrm{C}$ for $2 \mathrm{~h}$ transformed the amorphous film into polycrystalline anatase $\mathrm{TiO}_{2}$.

Scanning electron microscope (SEM) images are shown in Figure 2 to demonstrate the result of each step described above. Figure 2a shows a monolayer of self-assembled PS spheres coated with $\mathrm{TiO}_{2}$, which exhibits a very smooth surface due to the low growth temperature. The spaces between the spheres are partially filled as a result of the $\mathrm{TiO}_{2}$ growth. The sample surface after ion milling is shown in Figure 2b. The blue triangles are $\mathrm{TiO}_{2}$ shells with a uniform thickness of $\sim 24 \mathrm{~nm}$. This reveals that the growth per cycle of amorphous $\mathrm{TiO}_{2}$ on the PS spheres is about $0.12 \mathrm{~nm}$ at $80{ }^{\circ} \mathrm{C}$, a little higher than growth at $100{ }^{\circ} \mathrm{C}$, as expected from the increased number of hydroxyl groups present on the surface at low temperatures. The brown region among the triangles is the milled polystyrene surface, which is slightly lower than the $\mathrm{TiO}_{2}$ surfaces owing to a higher milling rate of polystyrene.

Highly ordered arrays of $\mathrm{TiO}_{2}$ nanobowls were fabricated after toluene etching. As shown in Figure 2c, the periodic structure was well preserved during the entire process. No distortion was observed on the thin walls of $\mathrm{TiO}_{2}$ after sonicating in toluene for $1.5 \mathrm{~min}$. The bright spot at the center

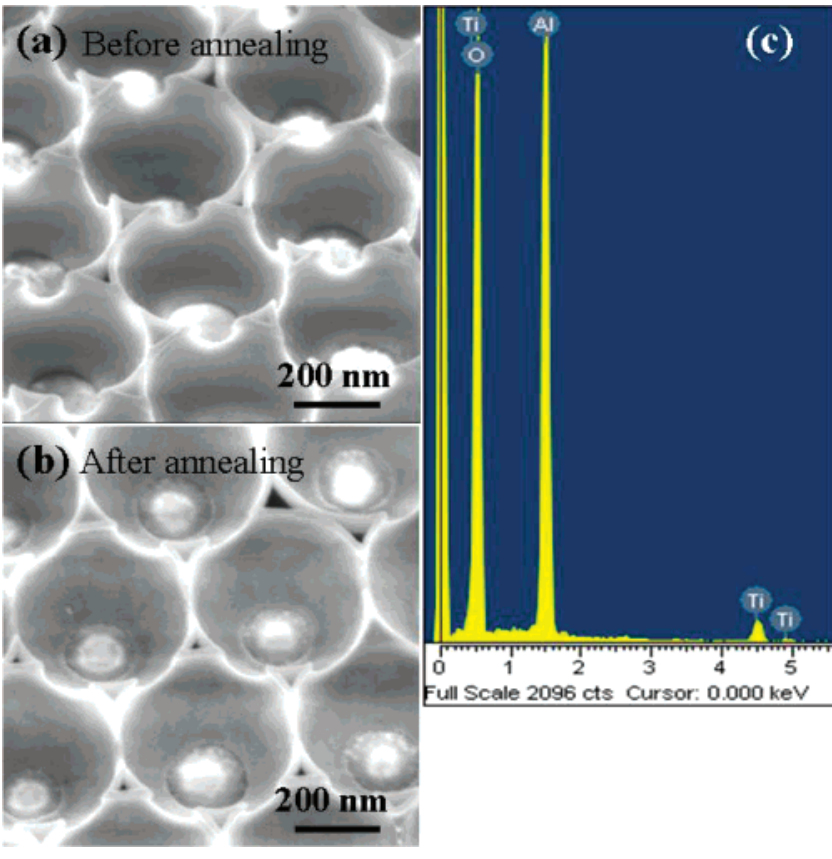

Figure 3. High-temperature annealing was used to transform the amorphous structured walls into polycrystalline walls. $\mathrm{TiO}_{2}$ nanobowls before (a) and after (b) annealing at $850{ }^{\circ} \mathrm{C}$. (c) EDS spectra recorded from the $\mathrm{TiO}_{2}$ nanobowls after annealing.

of each bowl is the exposed $\mathrm{Al}_{2} \mathrm{O}_{3}$ substrate, which was masked from $\mathrm{TiO}_{2}$ deposition at the PS sphere contact points. The inset in Figure 2c is a high-magnification image of the $\mathrm{TiO}_{2}$ bowls, from which the spherical shape and the smooth interior surface of the bowls can be clearly seen. The notches between the bowls are the result of the contact point between PS spheres.

The amorphous $\mathrm{TiO}_{2}$ nanobowls can be converted into polycrystalline nanobowls by annealing. After annealing at $850^{\circ} \mathrm{C}$ for $2 \mathrm{~h}$ in air, nanobowls composed of nanocrystallites were produced. Representative images of the $\mathrm{TiO}_{2}$ bowls before and after annealing are shown in Figure $3 a$ and $b$, respectively. By comparing these two pictures, no obvious size shrinkage was induced: the diameter of the bowls remains at $\sim 460 \mathrm{~nm}$ and the thickness of the $\mathrm{TiO}_{2}$ wall measured at the triangular region is also constant at $24 \sim 25$ $\mathrm{nm}$. Furthermore, the annealing process does not obviously change the smoothness of the interior surface, although there is a small roughness around the contact region between the $\mathrm{TiO}_{2}$ bowls and the substrate. The chemical composition of the bowls after annealing is confirmed by energy-dispersive $\mathrm{X}$-ray spectroscopy (EDS) (Figure 3c). In addition to Ti and $\mathrm{O}$ peaks, $\mathrm{Al}$ is also shown, which attributed to the substrate.

The crystallography of the annealed $\mathrm{TiO}_{2}$ was examined using a Hitachi HF2000 transmission electron microscope (TEM). A low-magnification TEM image is shown in Figure 4a. The $\mathrm{TiO}_{2}$ bowls were broken for the TEM specimen preparation. However, their spherical shape can still be seen. The strong contrast of the wall is due to the larger projected mass thickness. The inset in Figure $4 \mathrm{a}$ is a typical diffraction pattern recorded on the $\mathrm{TiO}_{2}$ bowls, indicating their polycrystalline structure. The anatase crystal structure is confirmed by the diffraction pattern. ${ }^{14}$ Although the $\mathrm{TiO}_{2}$ bowls 

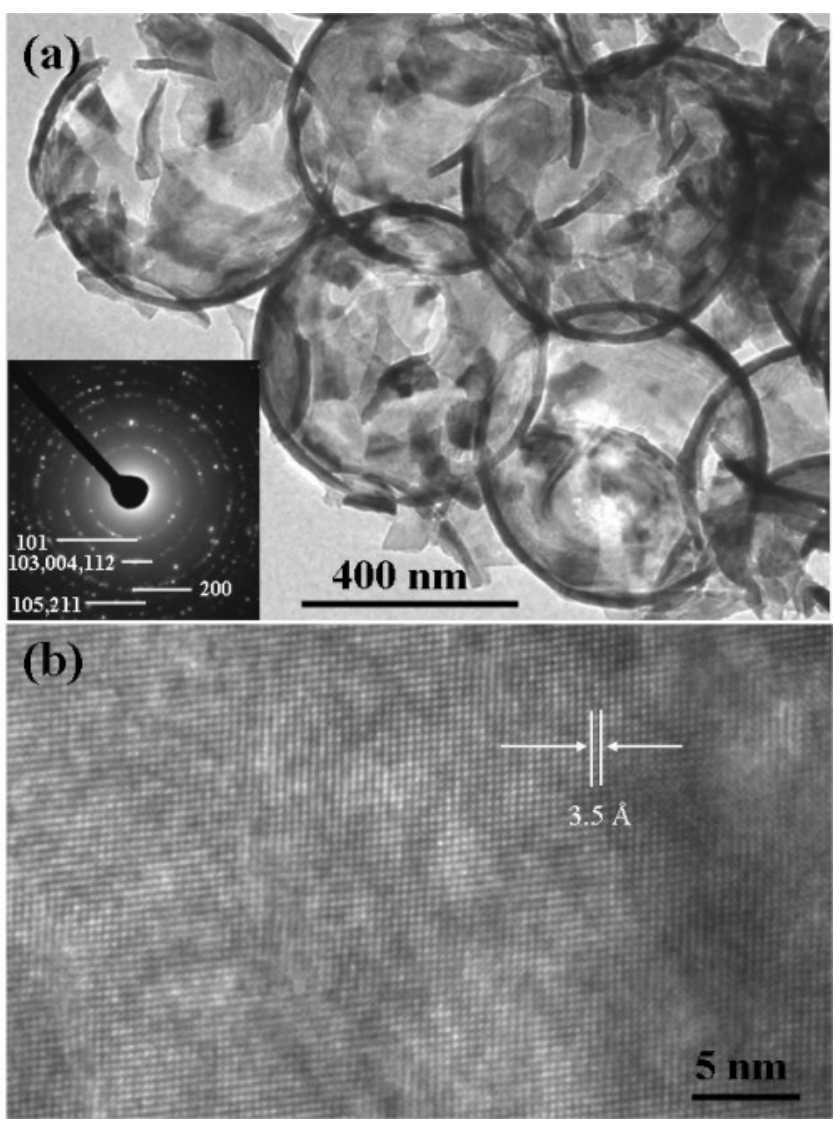

Figure 4. Crystallographic structure of the $\mathrm{TiO}_{2}$ nanobowls. (a) Low magnification TEM image of $\mathrm{TiO}_{2}$ nanobowls. (inset) Diffraction pattern recorded from $\mathrm{TiO}_{2}$ nanobowls. (b) High-resolution TEM image of the wall of a $\mathrm{TiO}_{2}$ nanobowl.

exhibit a polycrystalline structure, their grain size is fairly large, typically $50 \mathrm{~nm}$. A high-resolution TEM image recorded from a $\mathrm{TiO}_{2}$ nanocrystal is shown in Figure 4b. The uniform lattice fringe spacing is indicative of the high quality of the nanocrystal. The distance between each fringe is about $3.5 \AA$, corresponding to the interplanar distance of $\{101\}$.

As one of the important functional semiconductors, $\mathrm{TiO}_{2}$ exhibits promising applications in solar cell, ${ }^{15,16}$ photocatalytic, ${ }^{17}$ photonic crystal, ${ }^{18,19}$ and photovoltaic ${ }^{20}$ technology. As described above, robust and highly ordered anatase $\mathrm{TiO}_{2}$ nanobowl arrays have been successfully fabricated, and their larger open surface area could significantly increase the efficiency of surface related phenomena. The fabrication technique could also be applied to different substrates that have smooth and hydrophilic surfaces, such as silicon, glass, metals, or even polymers. This will broaden its application in various fields. The nanobowls could also be lifted off the substrate to form monolayer submicron filters. Moreover, the thickness of the $\mathrm{TiO}_{2}$ wall can be precisely tuned by varying the number of ALD cycles, and the bowl size can be adjusted by using different sized PS spheres during the formation of the templates. Therefore, these nanobowl arrays could be good candidates as size separators and containers for fine particles, or even for bio species such as cells if the interior surface is coated with functional groups. The following experiment demonstrates a potential application.
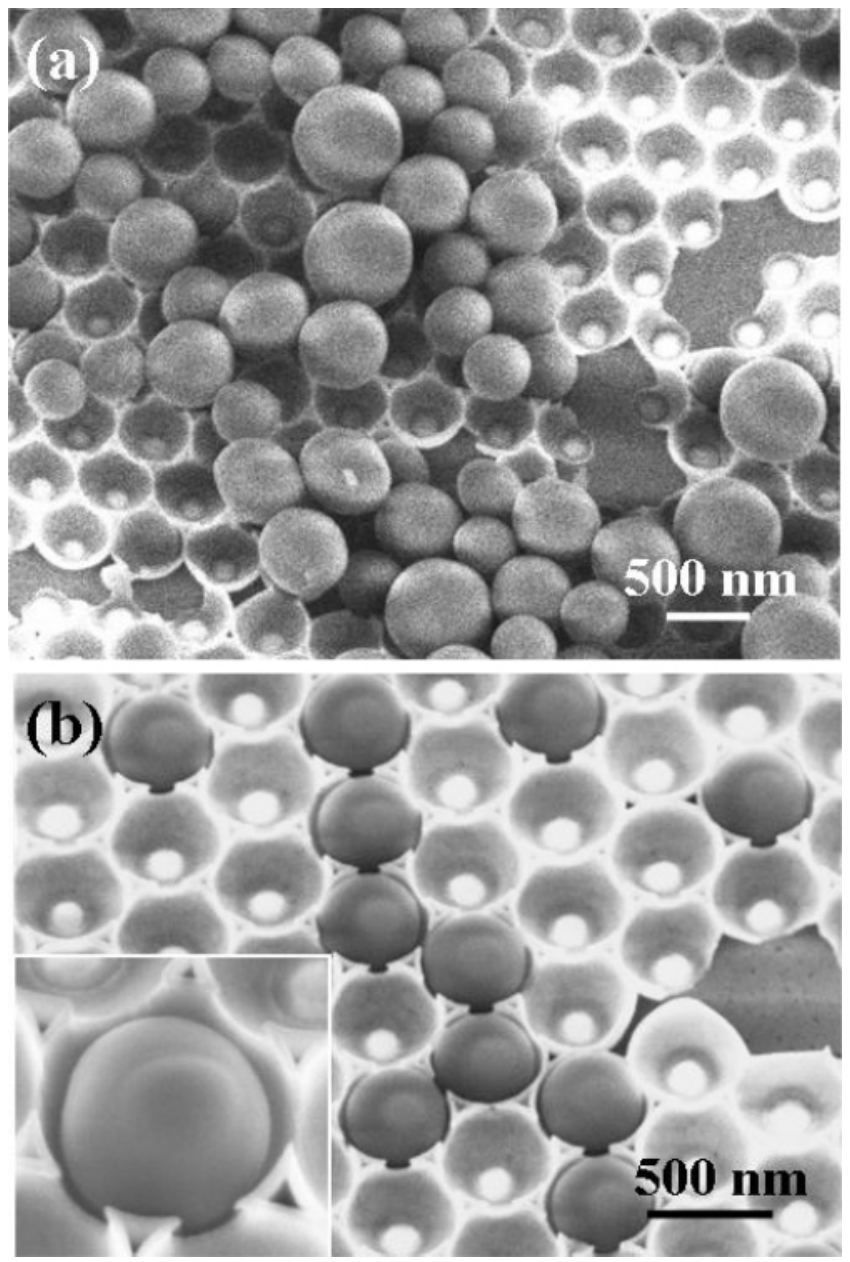

Figure 5. (a) Different sized PS spheres lying on the top of a $\mathrm{TiO}_{2}$ nanobowl array after applying a drop of PS spheres with mixed sizes. (b) Only the smallest PS spheres remain after washing with ethanol. (inset) A $450 \mathrm{~nm}$ PS sphere confined inside a $\mathrm{TiO}_{2}$ nanobowl.

A mixture of PS spheres with different sizes was used to demonstrate that the $\mathrm{TiO}_{2}$ bowls can be used for selecting monosized submicron spheres. In the following experiment, equal amounts of PS spheres of diameters $450 \mathrm{~nm}, 590,680$, and $820 \mathrm{~nm}$ were added into $10 \mathrm{~mL}$ of ethanol, forming a $0.5 \%$ (by weight) PS sphere suspension. One droplet of the suspension was applied onto the crystallized $\mathrm{TiO}_{2}$ bowls and sonicated for $15 \mathrm{~s}$. As shown in Figure 5a, PS spheres that are larger than the inner diameter of the $\mathrm{TiO}_{2}$ bowls $(\sim 460$ $\mathrm{nm}$ ), are distributed on the top of the bowls. Only the smaller PS spheres with a diameter of $450 \mathrm{~nm}$ fell into the $\mathrm{TiO}_{2}$ bowls. Then, a small amount of ethanol was sprayed onto the substrate to wash away the PS spheres. All of the larger spheres were flushed away, and only the small sized spheres remained inside the bowls (Figure 5b). The inset in Figure $5 \mathrm{~b}$ shows that a PS sphere that is located inside a $\mathrm{TiO}_{2}$ bowl is well surrounded and protected so that it was not flushed away by the ethanol. Due to the low concentration of PS spheres in suspension, only a small percentage of the $\mathrm{TiO}_{2}$ bowls were occupied. A repeat of the above process may select all of the smaller spheres. This simple experiment illustrates that $\mathrm{TiO}_{2}$ bowl arrays are useful for selecting particles smaller than their inner diameter. 
In summary, we presented an effective approach for fabricating highly ordered anatase $\mathrm{TiO}_{2}$ bowl arrays. The process utilizes a self-assembled monolayer of PS spheres as a template. $\mathrm{TiO}_{2}$ walls are uniformly coated on the sphere surface by atomic layer deposition, with which the thickness of $\mathrm{TiO}_{2}$ walls can be precisely controlled. The final nanobowl arrays were achieved after ion milling, etching, and annealing. In addition to their inherited well-ordered arrangement, the nanobowls also exhibit smooth interior and exterior surfaces and uniform size and thickness. $\mathrm{TiO}_{2}$ nanobowls could potentially be applied to solar cell, photocatalysis, and photovoltaic technology. The nanobowls have been demonstrated for selecting spheres smaller than the inner diameter of the bowls. The approach presented in this paper could be extended to a wide range of coating materials and substrates, with controlled wall thickness and size.

\section{References}

(1) Haynes, C. L.; Van Duyne, R. P. J. Phys. Chem. B 2001, 105, 5599.

(2) Hulteen, J. C.; Van Duyen, R. P. J. Vac. Sci. Technol. A 1995, 13, 1553.

(3) Rybczynski J.; Ebels, U.; Giersig M. Colloids Surf. A 2003, 219, 1.

(4) Kosiorek, A.; Kandulski, W.; Chudzinski, P.; Kempa, K.; Giersig M. Nano Lett. 2004, 4, 1359.
(5) Kempa, K.; Kimball, B.; Rybczynski, J.; Huang, Z. P.; Wu, P. F.; Steeves, D.; Sennett, M.; Giersig, M.; Rao, D. V. G. L. N.; Carnahan, D. L.; Wang, D. Z.; Lao, J. Y.; Li, W. Z.; Ren, Z. F. Nano Lett. 2003, 3, 13 .

(6) Wang, X. D.; Summers, C. J.; Wang, Z. L. Nano Lett. 2004, 4, 423.

(7) Suntola, T. Mater. Sci. Rep. 1989, 4, 261.

(8) Leskela, M.; Ritala, M. Thin Solid Films 2002, 409, 138.

(9) King, J. S.; Neff, C. W.; Summers, C. J.; Park, W.; Blomquist, S.; Forsythe, E.; Morton, D. Appl. Phys. Lett. 2003, 83, 2566.

(10) King, J. S.; Neff, C. W.; Blomquist, S.; Forsythe, E.; Morton, D.; Summers, C. J. Phys. Status Solidi 2004, 241, 763

(11) Chen, P.; Mitsui, T.; Farmer, D. B.; Golovchenko, J.; Gordon, R. G.; Branton, D. Nano Lett. 2004, 4, 1333.

(12) Shin, H.; Jeong, D. K.; Lee, J.; Sung, M. M.; Kim, J. Adv. Mater. 2004, 16, 1197.

(13) Heineman, D. M.S. Thesis, 2004

(14) Burdett, J. K.; Hughbanks, T.; Miller, G. J.; Richardson, J. W.; Smith, J. V. J. Am. Chem. Soc. 1987, 109, 3639.

(15) O’Regan, B.; Grätzel, M. Nature 1991, 353, 737.

(16) Nazeeruddin, M. K.; Humphry-Baker, R.; Officer, D. L.; Campbell, W. M.; Burrell, A. K.; Grätzel, M. Langmuir 2004, 20, 6514.

(17) Linsebigler, A. L.; Lu, G.; Yates, J. T. Chem. Rev. 1995, 95, 735.

(18) King, J. S.; Heineman, D.; Graugnard, E.; Summers, C. J. Appl. Surf. Sci. 2004, in press.

(19) King, J. S.; Graugnard, E.; Summers, C. J. Adv. Mater. In press, 2004.

(20) Ma, T.; Inoue, K.; Yao, K.; Noma, H.; Shuji, T.; Abe, E.; Yu, J.; Wang, X.; Zhang, B. J. Electroanal. Chem. 2002, 537, 31.

NL048589D 